\title{
Linear psoriasis
}

\section{Wei Li MD, Xiao-Yong Man MD PhD}
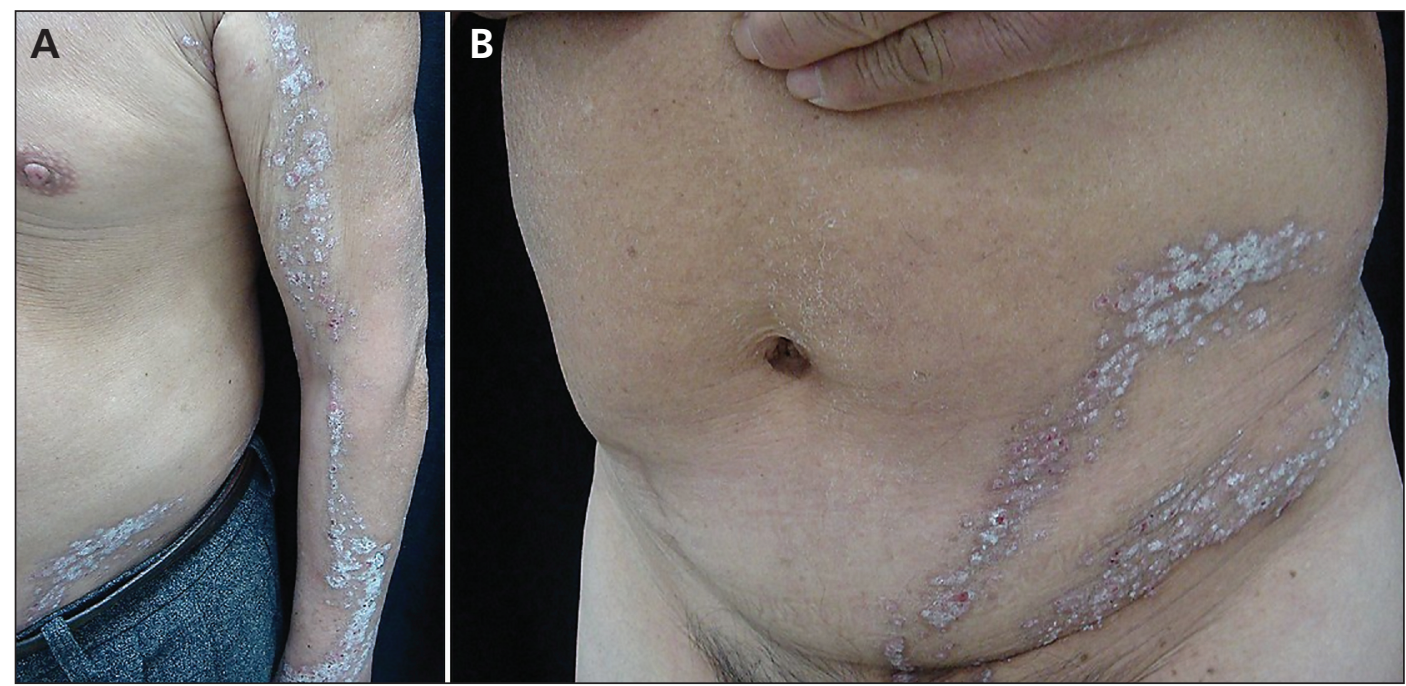

Competing interests: None declared.

This article has been peer reviewed.

Affiliation: From the

Department of

Dermatology, Second

Affiliated Hospital,

Zhejiang University School

of Medicine, Hangzhou,

Zhejiang, China

Correspondence to:

Dr. Xiao-Yong Man,

manxyzju@gmail.com

CMAJ 2012. DOI:10.1503

/cmaj.110866

Figure 1: Distribution of scaly plaques along Blaschko lines on the left arm (A) and flank (B) of a 69-year-old man.

A 69-year-old man presented with a 40year history of recurrent asymptomatic rashes on the left side of his body. Examination showed linear scaly plaques on his left arm (Figure 1A), the left side of his chest and abdomen, the left flank (Figure 1B) and the left leg, distributed along Blaschko lines (invisible lines on the skin that may represent fetal epidermal cell migration). Auspitz sign (the appearance of multiple fine bleeding points after gently scraping the scaly plaques) was positive. Histopathologic findings from a skin biopsy taken from the left forearm were diagnostic of psoriasis (Appendix 1, available at www.cmaj.ca /lookup/suppl/doi:10.1503/cmaj.110866/-/DC1). On the basis of these clinical and histopathologic signs, we confirmed the diagnosis of linear psoriasis. Following treatment with topical calcipotriol-betamethasone diproprionate ointment for six weeks, the patient's skin condition nearly cleared up; however, the lesions returned four weeks after treatment was stopped.

Psoriasis is a common, chronic, inflammatory and proliferative skin disorder, affecting about $2 \%$ of the population. Linear psoriasis is an unusual subtype characterized by a distribution of the psoriatic lesions along Blaschko lines. The main differential diagnosis is inflammatory linear verrucous epidermal nevus, which also follows Blaschko lines but usually begins in infancy. This condition is intensely pruritic and usually resistant to antipsoriatic therapies. In contrast, linear psoriasis tends to be of late onset, is generally asymptomatic or only mildly pruritic and responds well to topical or systemic antipsoriatic treatment. ${ }^{1}$ There may be an association between its distribution along Blaschko lines, human leukocyte antigen (HLA) class I alleles ${ }^{2}$ and somatic recombination. ${ }^{3}$

Systemic treatments for linear psoriasis are not recommended unless the skin lesions are particularly burdensome and cannot be controlled with topical agents or narrow-band ultraviolet B phototherapy. ${ }^{4}$

\section{References}

1. Happle R. Linear psoriasis and ILVEN: Is lumping or splitting appropriate? Dermatology 2006;212:101-2.

2. Magalhães RF, Velho PE, Machado de Moraes A, et al. Linear psoriasis in Brazilian children and HLA haplotypes. J Eur Acad Dermatol Venereol 2007;21:1439-40.

3. Happle R. Somatic recombination may explain linear psoriasis. J Med Genet 1991;28:337.

4. Menter A, Korman NJ, Elmets CA, et al. Guidelines of care for the treatment of psoriasis and psoriatic arthritis: case-based presentations and evidence-based conclusions. J Am Acad Dermatol 2011;65:137-74 